\title{
IMPLEMENTATION OF RADIO URBANRKM 99.5 FM REBRANDING TO CREATE COMPANY'S NEW IMAGE
}

\author{
Karina Putri Palasari Triyana, Aan Setiadarma \\ Program Studi Ilmu Komunikasi FISIP UPN “ Veteran” Jakarta \\ e-mail: aan.setiadarma@gmail.com
}

\begin{abstract}
Background of research is there is a rebranding of URBANrkm 99.5 FM become Smooth Radio who have very different characteristics that caused by changing ownership. Rebranding makes the company should face all of external stakeholder's respons and doing all steps implementations of any changes to create the company's new image. The theory used is communication, public relations, implementation, rebranding and the concept definitions of image. Research Methode used is qualitative approuch with descriptive as the type of research. Key informan of this research is the Director Program of URBANrkm 99.5 FM Radio and Smooth Radio, with three informants, marketing communications of Smooth Radio, and two loyal listener of URBANrkm 99.5 FM Radio. Research Result, in making program and public relation's activities on rebranding phase, Smooth Radio use five steps of implementation that appropriate with Wheelen and Hunger's theory, there are also some change that done by Smooth Radio to create their new image. Conclusion, URBANrkm 99.5 FM Radio succesed to maintain their image on external stakeholder's eyes when their crisis time through their public relation's activities that they done. In another hand, Smooth Radio also succesed to show their image through all implementation's step they done and by changing their identity with some evaluation that should to be their attention.
\end{abstract}

Keyword: public relations, rebranding, radio, image

\begin{abstract}
ABSTRAK
Latar belakang penelitian ini adalah terjadinya rebranding Radio URBANrkm 99.5 FM yang mengalami perubahan kepemilikan sehingga berubah menjadi Smooth Radio yang memiliki kharakteristik yang sangat berbeda. Rebranding membuat perusahaan harus menghadapi respon dari stakeholder eksternal dan mengimplementasikan setiap perubahan guna meniciptakan citra baru perusahan. Landasan Teorinya digunakan adalah komunikasi, public relations, rebrandaing, dan definisi konsep citra.. Metode Penelitian yang digunakan adalah pendekatan penelitian kualitatif dengan jenis penelitian deskriptif. Adapun key Informan penelitian ini adalah Program Director Radio URBANrkm99.5 FM dan Smooth Radio, dengan tiga informan yakni Marketing Comunications Smooth Radio, dan dua pendengar setia Radio URBANrkm 99.5 FM. Hasil Penelitian, dalam membuat program dan kegiatan kehumasan pada masa rebranding, Smooth Radio menggunakan lima tahapan implementasi yang sesuai dengan Teori Wheelen and Hunger, selain itu adapula beberapa perubahan yang dilakukan Smooth Radio guna menciptakan citra baru perusahaan. Kesimpulan, Radio URBANrkm 99.5 FM berhasil mempertahankan citranya dimata stakeholder eksternal pada masa krisisnya melalui kegiatan
\end{abstract}


kehumasan yang dilaksanakan. Smooth Radio juga berhasil mulai memunculkan citra perusahaan melalui implementasi dan perubahan identitas yang dilakukan dengan beberapa evaluasi yang perlu diperhatikan.

\section{Kata Kunci: public relations, rebranding, radio, citra}

\section{PENDAHULUAN}

Radio URBANrkm 99.5 FM merupakan Stasiun Radio Swasta di Jakarta yang sedang berkembang. Radio yang saat ini memiliki 5 program siaran dalam satu hari ini dahulunya pernah mengalami proses rebranding dari sebuah Stasiun Radio yang tradisional dan bersegmentasi dewasa yakni Radio Kayu Manis. Radio Kayu Manis (RKM) merupakan salah satu Radio yang sangat terkenal pada tahun 1990an dan merupakan salah satu radio perintis di Indonesia. Dengan mengusung banyak program kebudayaan, Radio Kayu Manis bertahan di industri penyiaran hingga lebih dari 30 tahun. Radio ini memiliki segmentasi pria dan wanita dewasa dengan usia 30-70 tahun. Musik dan program yang disiarkan pun menyesuaikan dengan usia pendengarnya. Industri penyiaran di Indonesia, dan semakin majunya teknologi di dunia, membuat Radio Kayu Manis memutuskan untuk "memodernkan" diri, salah satunya dengan resmi berganti nama menjadi RadioURBANrkm, sejak tanggal 01 Mei 2013.

Dengan format AC atau Adult Contemporer yang lebih modern, Radio URBANrkm hadir bagi pendengar yang berusia 18-34 tahun. Selain program yang menarik dan penyiar yang menghibur, warna musik juga menjadi salah satu kekuatan yang dimiliki oleh Radio URBANrkm, karena pada awalnya URBAN rkm mendominasikan musik terbaik Indonesia sehingga memilih jargon atau slogan "Musik Indonesia yang Gak Ada Matinya!! Namun, seiring berjalannya waktu, mengikuti perkembangan zaman URBANrkm menambah komposisi musik yang disiarkanya dengan musik hits internasional, dengan presentasi $60 \%$ musik Indonesia dan $40 \%$ musik internasional baik dari tahun 90-an hingga saat ini, sehingga URBANrkm memilih berganti slogan menjadi "Musik yang Gak Ada Matinya !!'Berdasarkan Survey AC Nielsen, saat ini Radio URBANrkm menjadi salah satu Radio yang masuk 10 besar Radio teratas di Jakarta dan sekitarnya. Berada di posisi ke-6, dengan jumlah pendengar 1.031.000, Radio URBANrkm menjadi Radio nomor 2 dengan format Radio Pop di seluruh Jakarta dan sekitarnya. Tertanggal Februari 2015, Radio URBANrkm 99.5 FM meraih \pm 13.000 Followers twitter, peningkatan 
sejumlah \pm 2.000 followers dalam jangka waktu 2 bulan.

Dalam kondisi perkembangan Radio URBANrkm 99.5 yang sedang meningkat, muncul isu bahwa Radio ini akan berubah kepemilikan, sebelumnya Pemilik dari Radio URBANrkm 99.5 FM adalahMalik Sjafei dan tergabung dalam MAHAKA grup.Penyiaran program mulai dikurangi hari demi hari, hingga akhirnya disahkan bahwa tertanggal 28 Februari 2015 Radio URBANrkm 99.5 FM selesai mengudara, dan tertanggal 01 Maret 2015 Radio tersebut akan launching nama \& kepemilikan baru dari Radio tersebut. Radio tersebut dibeli oleh suatu Perusahaan Media Group dari Singapura bernama MPG Media Publishing Group.

MPG Media Publishing Group merupakan sebuah perusahaan yang bergerak di bidang Media Massa \& Publikasi, sebelumnya MPG Media Publishing Group sudah memiliki beberapa media massa seperti Nylon Magazine, Indonesia Baccarat, Luxury Magazine, HWM Indonesia, Home \& Decor. Dan saat ini MPG Media Publishing Group mencoba untuk membuat radio pertama dalam naungan grup mereka, yakni dengan membeli Radio URBANrkm 99.5.

Pada proses rebranding tersebut, tentunya Radio ini mengalami masa transisi yang cukup signifikan, seperti yang diketahui bahwa radio ini telah mengalami dua kali proses rebranding, dari Radio Kayu Manis menjadi Radio URBANrkm dan rebranding kembali menjadi Radio yang akan launching nama barunya di awal bulan Maret tersebut. Perubahan yang terjadi adalah perubahan segmentasi yang kembali menjadi Radio untuk Dewasa (adult) usia 25-60 tahun atau bisa dikatakan kembali seperti segmentasi Radio Kayu Manis. Perubahan terjadi pula pada sumber daya manusia atau karyawan dari Radio tersebut, hanya tersisa empat orang karyawan Radio URBANrkm 99.5 FM yang melanjutkan atau terpilih untuk menjadi karyawan di Radio baru tersebut nantinya.

Kegiatan Public Relations mencakup dua hal yakni kegiatan internal public relations dan eksternal public relations, selain itu fungsi public relations juga terbagi dua yakni methode of communicationi dan state of being. Mayoritas perusahaan radio termasuk Radio URBANrkm dan Smooth FM menggunakan fungsi public relations yaitu methode of communications, yakni public relations tidak ada dalam struktural namun kegiatannya tetap berlangsung dan dilaksanakan.Dalam proses ini, implementasi kegiatan public relations dalam kondisi rebranding ini sangatlah dibutuhkan untuk mempertahankan hubungan baik antara perusahaan dengan stakeholder internal maupun eksternal 
perusahaan tersebut. Dalam ruang lingkup internal public relations, peran public relations dalam kondisi rebranding Radio ini sangat dibutuhkan untuk mempersiapkan strategi komunikasi yang sesuai untuk situasi perusahaan yang kelak diisi oleh orang - orang yang baru dan juga yang sebelumnya dari Radio URBANrkm 99,5FM, iklim organisasi perusahaan pun berubah, public relations dituntut untuk membuat kondisi antar karyawan bersinergi dan memiliki sense of belonging terhadap perusahaan baru sehingga dapat menciptakan dan meningkatkan kerjasama seluruh karyawan untuk membangun citra positif radio baru dari titik nol. Berkaitan dengan adanya perubahan karyawan tersebut, akan berdampak pula naik turunnya iklim organisasi tersebut yang harus dikontrol dan ditangani oleh public relations.

Sedangkan dalam ruang lingkup eksternal public relations, peran Public Relations sangatlah dibutuhkan untuk mempertahankan citra dan pendengar setia Radio URBANrkm 99.5 FM tersebut agar tetap menjadi pendengar atau stakeholder eksternal dari Radio baru tersebut nantinya, karena saat ini Radio URBANrkm 99,5 FM memiliki cukup banyak pendengar setia. Selain itu, Public Relations juga sangat dibutuhkan untuk mempersiapkan strategi komunikasi yang sesuai dengan kondisi perusahaan untuk menyampaikan krisis atau proses rebranding tersebut kepada pihak Eksternal yang menanyakan perubahan - perubahan yang terjadi. Berkaitan dengan salah satu tugas public relations yaitu mempertahankan hubungan yang tetap harmonis dan sinergis antara perusahaan dengan stakeholder eksternal, khususnya pendengar \& media massa, public relations juga bertugas untuk menciptakan citra baru dari perusahaan radio baru tersebut sesuai dengan segmentasi dan visi misi perusahaan. Pembentukan citra baru tersebut tergantung pada bagaimana implementasi dari kegiatan - kegiatan eksternal public relations radio baru tersebut, diharapkan citra yang terbentuk merupakan citra positif yang mampu meningkatkan nama baik dan eksistensi radio baru tersebut.

\section{TINJAUAN PUSTAKA}

\section{Public Relations}

Cutlip, Center, dan Broom( Butterick : 2012), mendefinisikan PR sebagai berikut : 'Public Relations adalah fungsi manajemen yang mengidentifikasi, membangun, dan mempertahankan hubungan yang saling menguntungkan antara organisasi dengan berbagai publik yang menjadi penentu kesuksesan dan kegagalannya'.

Menurut Maria (Nurjaman dan Umam :2012, hlm. 114-115) 'Public relations merupakan satu bagian dari satu 
napas yang sama dalam organisasi tersebut, dan harus memberi identitas organisasinya dengan tepat dan benar serta mampu mengomunikasikannya sehingga publik menaruh kepercayaan dan mempunyai pengertian yang jelas dan benar terhadap organisasi tersebut'.

Menurut Ruslan (Ruslan : 2008) pada dasarnya ada empat peran Public Relations, yakni :

1. Sebagai Communicator, atau penghubung antara organisasi atau lembaga yang diwakili dengan publiknya. Dari uraian tersebut dijelaskan Public relations berperan sebagai perwakilan perusahaan dalam melakukan komunikasi dengan publik internal dan eksternal.

2. Membina relationship, yaitu berupaya membina hubungan yang positif dan saling menguntungkan dengan pihak publiknya. Dalam hal ini Public relations berperan dalam melakukan pendekatan hubungan baik dengan publik.

3. Peranan back up management, yakni sebagai pendukung organisasi selalu sigap dalam menjalankan tugas dari atasan/perusahaan.

4. Membentuk coorporate image, artinya peranan Public Relations berupaya mencipatakan citra bagi organisasi atau lembaganya. Dalam hal ini Public relations berperan menjaga dan menciptakan citra yang positif terhadap perusahaan dimata publik.

Menurut Wheelen dan Hunger (Iriantara : 2013, hlm 123), 'Implementasi adalah himpunan kegiatan dan pilihan yang diperlukan untuk menjalankan rencana. Implementasi ini tidak lain merupakan proses menjabarkan strategi dan kebijakan ke dalam tindakan dengan mengembangkan program, anggaran, dan prosedur. Dalam memulai implementasi, ada tiga pertanyaan yang menurut Wheelen dan Hunger harus dijawab, yaitu :

a. Siapa orang yang akan menjalankan rencana strategis itu?

b. Apa yang harus dilakukan?

c. Bagaimana cara melakukan apa yang diperlukan?

Ketiga pertanyaan tersebut, pada dasarnya berkenaan dengan sumber daya manusia yang akan menjalankan rencana pembagian tugas dan adanya prosedur baku dalam melaksanakan kegiatan tersebut. Istilah manajemen tersebut mencakup pengorganisasian (organizing), penyusunan (staffing), pengarahan (directing), pengawasan (controlling), dan penilaian (evaluating).

1. Pengorganisasian (Organizing)

R. Terry dalam (Iriantara : 2010, hal.126) menjelaskan bahwa 'Pengorganisasian merupakan kegiatan dasar manajemen yang dilakukan untuk menghimpun dan menyusun semua sumber daya yang 
diisyaratkan dalam rencana sehingga kegiatan mencapai tujuan yang sudah ditetapkan bisa dilaksanakan dengan baik'.

\section{Penyusunan (Staffing)}

Setelah pengorganisasian dilakukan, langkah berikutnya adalah penyusunan sumber daya manusia yang diperlukan untuk mengisi kelompok - kelompok tugas yang ada. Penyusunan sumber daya manusia itu dilakukan berdasarkan dua pendekatan yakni berdasarkan kuantitas dan kualitas sumber daya manusianya. Manulang dalam (Iriantara : 2010, hal 132) 'ada tiga hal yang perlu diperlukan dalam kualifikasi tenaga yaitu keahlian, pengetahuan tentang organisasi dan loyalitas'

\section{Pengarahan (Directing)}

Tujuan pengarahan dalam suatu kegiatan pada dasarnya adalah mengoordinasikan bagian - bagian tugas agar tetap berjalan dengan baik dalam upaya mencapai tujuan yang sudah ditetapkan sebelumnya. Melalui pengarahan ini, bila terjadi kekeliruan maka dikoreksi atau bila pekerjaan dilaksanakan terlalu lambat didorong untuk dipercepat. Termasuk pula didalamnya upaya memberi motivasi untuk bekerja lebih baik atau lebih giat. Menurut Djudju dalam (Iriantara : 2010, hal. 134) 'pemberian motivasi terdapat tiga pendekatan yang biasanya dilakukan yakni ; kemitraan (partnership), produktivitas (productivity), dan pemuasan keinginan (wants satisfications)'.

\section{Pengawasan (Controling)}

Menurut Manulang dalam (Iriantara : 2010, hal.138) 'Pengwasan bertujuan untuk mengusahakan apa yang direncanakan bisa menjadi kenyataan. Sedangkan pengawasan sendiri dapat diartikan sebagai "proses untuk menetapkan pekerjaan apa yang sudah dilakukan, menilai pekerjaan tersebut dan mengoreksinya bila diperlukan dengan maksud agar pelaksanaan pekerjaan sesuai dengan rencana'.

\section{Penilaian (Evaluating)}

Manulang dalam (Iriantara : 2010, hal. 141) mengatakan " Dengan demikian penilaian pada dasaranya membandingkan antara hasil nyata (aktual) dengan hasil yang diinginkan atau diharapkan.' Dengan begitu dapat ditempuh langkah - langkah perbaikan untuk program atau kegiatan selanjutnya.

\section{Rebranding}

Rebranding adalah perpaduan dari kata "re" dan "branding", kata " $r e$ " berarti kembali, "branding" berarti proses penciptaan brand. 'Rebranding adalah sebuah praktek dari pembentukan nama baru yang merepresentasikan perubahan posisi dalam mind frame para stakeholder dan pembedaan identitas dari kompetitornya'.(Muzellec et.al, 2003). Rebranding secara definisi berarti perubahan identitas, yang harus dilihat 
sebagai sebuah keputusan strategis dengan rencana yang matang.(Daly dan Moloney, 2004) Perubahan identitas yang dimaksud adalah perubahan logo, nama, warna, dan hal hal lain yang menjadi jati diri sebuah perusahaan akibat faktor - faktor yang terjadi dibalik rebranding tersebut.

Rebranding dapat terjadi pada tiga level yang berbeda dalam sebuah organisasi yaitu: corporate rebranding, business unit, dan product levels. Corporate Rebranding berarti penamaan kembali corporate identity secara keseluruhan, yang sering kali mengindikasikan perubahan besar dalam level strategis atau repositioning. Sedangkan dalam level bisnis unit berarti, sebuah situasi dimana subsidiary atau divisi dalam satu perusahaan besar diberikan nama yang berbeda sebagai identitas yang berbeda dari perusahaan induknya. Untuk level individual produk, rebranding relatif jarang terjadi dan lebih kepada pergantian nama produk. (Muzellec et.al, 2003).

Peranan dan tugas Public Relations (Diyanti : 2012) didalam proses rebranding tersebut dapat berupa beberapa langkah seperti : Menciptakan strategi pembentukan brand ( positioning, nama, nilai dan identitas brand lainnya), memperkenalkan brand dalam mengurus citra, membangun komunitas brand dan membuat program program loyalitas terhadap brand..Public Relations bertugas untuk membentuk citra baru perusahaan yang mengalami proses rebranding tersebut juga menjaga hubungan baik perusahaan dengan stakeholder perusahaan dalam proses rebranding tersebut.

Untuk lebih menjelaskan bagaimana keterlibatan kegiatan public relations di dalam rebranding,H. Fayol dalam (Firsan : 2009) menjelaskan beberapa sasaran kegiatan PR adalah Membangun identitas dan citra perusahaan ( building coorporate identity and image),menghadapi krisis (facing crisis), Mempromosikan aspek kemasyarakatan (promotion ppublic causes).

\section{Citra}

Menurut Philip Henslowe (Henslowe, 2000:2) 'Citra adalah kesan yang diperoleh dari tingkat pengetahuan dan pengertian terhadap fakta (tentang orang-orang, produk atau situasi)'. Kemudian Kasali (2003:30) juga mendefinisikan 'Citra sebagai kesan yang timbul karena pemahaman akan suatu kenyataan. Pemahaman itu sendiri timbul karena adanya informasi'.

(Yulianti : 2007, hlm : 42) 'Ada empat hal yang prinsip dari tujuan public relations yakni :

1. Menciptakan citra yang baik,

2. Memelihara citra yang baik,

3. Meningkatkan citra yang baik,

4. Memperbaiki citra jika citra organisasi kita menurun atau rusak'. 
Dari serangkaian tugas di atas pada umumnya public relations menekankan tujuan pada aspek citra.

\section{METODOLOGI PENELITIAN}

Secara garis besar permasalahan yang diangkat adalah mengenai sebuah proses, maka metode penelitian yang tepat untuk mendukung penelitian ini adalah menggunakan pendekatan kualitatif. Metode penelitian kualitatif merupakan metode penelitian yang menggunakan data dan fakta sebagai media yang dapat diolah menjadi hasil penelitian tersebut. Sifat penelitian yang digunakan penulis adalah Penelitian Kualitatif deskriptif. Penulis menggunakan sifat penelitian ini karena data - data yang dibutuhkan dan dikumpulkan berupa kata - kata, kalimat, dan opini yang didapatkan melalui proses wawancara dan observasi yang diharapkan dapat mendeskripsikan tujuan penelitian. Key-informan, yaitu pihak yang dipilih oleh penulis sebagai narasumber utama dari penelitian ini. Key Informan penelitian ini adalah Ibu Firly Istighfarin selaku Program Director dari Radio URBANrkm dan Smooth Radio. Key informan ini dipilih sebab pihak ini adalah pihak yang mengetahui tahapan dan tahapan rebranding serta melalui masa rebranding tersebut sehingga dapat memberikan data yang valid. Pihak yang menjadi informan dalam penelitian ini adalah Bapak Adam
Apriyawan selaku Marketing Communications Smooth Radio, Misael \& Putri Ayu selaku pendengar setia Radio URBANrkm. Penulis memilih tiga pihak tersebut sebab pihak tersebut dapat memberikan informasi dan data pendukung dari pernyataan key informan.

\section{HASIL PENELITIAN DAN PEMBAHASAN}

Dalam pEnelitian ini penulis membahas dan meneliti tahapan implementasi rebranding dari sebuah radio swasta di Jakarta, yakni Radio URBANrkm 99.5 FM.alasan atau faktor yang membuat Radio URBANrkm 99.5 FM mengalami rebranding adalah bukan terjadinya suatu krisis atau permasalahan besar melainkan berakhirnya kerjasama antara RKM dengan URBAN Radio yang didukung pula dengan adanya proses jual beli yang tiba - tiba. Jika dikaitkan dengan definisi konsep mengenai rebranding yang disampaikan oleh Muzalec, bahwa rebranding memiliki tiga level berbeda yakni coorporate rebranding, business unit, dan product levels. Rebranding yang dilakukan radio URBANrkm termasuk pada level coorporate rebranding, pada level ini perubahan yang terjadi tidak hanya pada produk atau bagian dari perusahaan saja melainkan dari kepemilikan perusahaan tersebut. Corporate Rebranding berarti penamaan kembali corporate identity 
secara keseluruhan, yang sering kali mengindikasikan perubahan besar dalam level strategis atau repositioning.

Dalam masa transisinya yang cukup panjang, tentunya ada banyak respon dari stakeholder perusahaan, baik dari stakeholer internal maupun stakeholder eksternal perusahaan, baik respon positif maupun negatif. Radio URBANrkm 99.5 FM mengalami rebranding bukan diakibatkan oleh krisis atau permasalahan yang terjadi pada produk yang berdampak pada citra perusahaan, namun terjadinya rebranding terutama dalam situasi dan kondisi Radio URBANrkm yang secara tidak langsung harus menutup perusahaannya karena proses jual beli yang terjadi juga dapat dikategorikan sebagai sebuah krisis.

Berkaitan dengan dibutuhkannya peran public relations dalam rebranding tersebut, maka dapat dikatakan bahwa public relations memiliki peranan penting dalam sebuah perusahaan seperti yang dikatakan oleh Ruslan dalam (Ruslan : 2008) 'Ada empat peran public relations yakni: sebagai communicator, pembina reltionship, back up management, dan coorporate image'. Dalam situasi dan kondisi yang dialami oleh Radio URBANrkm, pada dasarnya radio tersebut membutuhkan peran public relations sebagai communicator dan coorporate image.
Berdasarkan pada hasil penelitian melalui wawancara yang telah penulis lakukan terhadap Ibu Firly Istighfarin sebagai key informan, Radio URBANrkm tidak memiliki divisi public relations pada struktural perusahaan tersebut, radio ini menganut sistem methode of communications yakni kegiatan kehumasan atau public relations dilakukan oleh semua pihak di dalam perusahaan.Hingga pada situasi dan kondisi terakhir operasional perusahaan, yang melaksanakan kegiatan public relations di radio tersebut adalah pihak - pihak yang bertahan hingga pergantian kepemilikan. Secara garis besar, hasil dari wawancara dengan key informan, ibu Firly Istighfarin berpendapat bahwa pihak perusahaan selalu melakukan kegiatan kehumasan terutama yang sifatnya sebagai communictor dan coorporate image, hal tersebut dibuktikan dengan langkah ibu Firly beserta beberapa pihak yang selalu merespon pertanyaan dan tanggapan pendengar mengenai rebranding tersebut, tidak hanya itu, pihak perusahaan yang diwakili oleh Ibu Firly, Bapak Agus dan Marketing Komunikasi Radio URBANrkm melakukan klarifikasi dan penyelesaian kontrak kerjasama secara kekeluargaan agar tercipta citra bahwa Radio URBANrkm mengakhiri operasionalnya dengan baik. 
Implementasi Rebranding Radio URBANrkm 99.5 FM menjadi Smooth Radio

Bauran implementasi terbagi menjadi lima tahapan yakni :

\section{Pengorganisasian}

Pada tahapan ini, penulis berpendapat bahwa pihak Smooth Radio telah cukup baik dalam tahap pengorganisasian ini, dengan perencanaan konsep yang sudah matang untuk setiap tahapannya, dan perencanaan pembagian tugas yang sangat mengejutkan, yakni dengan pembentukan suatu tim kecil yang hanya beranggotakan lima orang. Keputusan ini bisa berdampak baik ataupun buruk terhadap perusahaan. Pengambilan keputusan ini berdasarkan budaya organisasi owner dan top management yang memiliki latar belakang kewarganegaraan Asing yang secara stereotype menyukai segala sesuatu yang efektif. Dalam realisasinya tim kecil tersebut memang cukup efektif menurut pendapat pihak - pihak yang terlibat dalam tim kecil tersebut, namun tetap ada beberapa hal yang harus di evaluasi.

\section{Penyusunan}

Pihak Smooth Radio telah cukup baik dalam tahapan ini. Hingga saat ini walaupun Smooth Radio baru memiliki sumber daya manusia yang tidak banyak, namun kemampuan karyawan - karyawan tersebut beberapa memang tepat mengisi posisi - posisi yang ada. Namun, penulis berpendapat bahwa keberadaan rangkap jabatan di dalam struktural harus dipertimbangkan, karena mungkin top management berfikir untuk membuat efektif sumber daya manusia yang ada, namun perlu diperhatikan juga apakah dengan rangkap jabatan tersebut sudah sesuai dengan kalimat the right man in the right place, karena tidak dapat dipungkiri bahwa ketika seseorang berada di dua posisi yang berbeda, apakah kedua posisi tersebut sesuai dengan latar belakang karyawan yang mengisi posisi tersebut, dan untuk meminimalisir ketidak fokusan karyawan terhadap salah satu posisi.

\section{Pengarahan}

Menurut hasil penelitian, pengarahan yang dilakukan sudah tergolong baik karena terdapat pengarahan yang sifatnya hierarki sehingga meskipun melewati beberapa tahapan namun dapat pengarahan tersebut dapat sesuai dengan porsi dan pendekatan yang berbeda yang disesuaikan dengan level posisi atau jabatan. Selain itu, hasil wawancara dari key informan dan informan juga menunjukan bahwa mereka merasa pengarahan tersebut sudah cukup baik terutama dari Program Director terhadap tim kecilnya, karena PD tersebut juga sering memberikan pengarahan melalui pendekatan secara informal dan komunikasi yang santai serta memberikan motivasi 
terhadap karyawan lain. Hanya saja, pengarahan dari top management masih lebih sering secara formal, top management beberapa kali memang melakukan pengarahan secara informal namun intensitasnya tidak terlalu sering.

\section{Pengawasan}

Terdapat hal yang menarik dari hasil penelitian ini yang berkaitan dengan tahapan pengawasan, perkembangan teknologi memang mempermudah manusia dalam melakukan kegiatan dan memenuhi kebutuhannya, terbukti dengan keberadaan social media yang telah menjadi media dalam tahapan pengawasan ini.Melalui social media "whatsapp" khusunya pada fitur group, pimpinan dapat selalu melakukan pengawasan terhadap karyawannya, meskipun memang pengawasan tersebut dilakukan secara tidak langsung melainkan melalui bantuan sebuah media.Penulis berpendapat bahwa hal tersebut hingga saat ini masih menguntungkan, karena top management dari Smooth Radio masih berada di kantor pusat dan hanya beberapa kali menetap di Studio Smooth Radio. Jadi, pengawasan tetap berjalan walaupun pimpinan tidak bisa setiap hari menghadiri kantor atau studio karena kepentingan lainnya. Hal ini memang sangat membantu, dan penulis berpendapat bahwa cara ini dapat menjadi contoh untuk siapapun bahwa ketika dalam keadaan yang tidak memungkinkan, media masih dapat membantu keperluan manusia. Namun, hal yang harus diperhatikan adalah, pimpinan harus dapat membatasi juga pengawasan secara tidak langsung tersebut, guna mengantisipasi terjadi ketidak sesuaian laporan dengan realisasi dan mengantisipasi terjadinya miss komunikasi bahkan terjadinya jarak terlalu jauh antara pimpinan dan bawahan dikarenakan komunikasi langsung yang intensitasnya sangat berkurang.

\section{Penilaian}

Adapun beberapa evaluasi atau penilaian dari seluruh tahapan implementasi yang telah dilakukan oleh Smooth Radio adalah, pertama dari aspek pengorganisasian tim kecil yang telah dibuat oleh pimpinan atau top management memang sesuatu yang cemerlang dan berorientasi pada keefektifitasan, namun harus ada perbaikan dari perencanaan posisi atau jabatan yang dipersiapkan.

Hal tersebut berkaitan dengan evaluasi pada tahapan yang kedua yaitu penyusunan, rangkap jabatan memang bukan menjadi hal yang salah, namun akan lebih baiknya jika setiap jabatan atau posisi diisi oleh sumber daya manusia yang berbeda dan memiliki latar belakang yang sesuai dan cocok dengan posisi tersebut, sehingga berdampak pada pengoptimalan fokus karyawan terhadap job descriptions mereka. Selain itu, pada kedua tahapan awal ini evaluasi yang disampaikan oleh key informan dan 
informan adalah perlunya penambahan sumber daya manusia terutama untuk posisi public relations karena pada pembentukan sebuah perusahaan yang diharapkan oleh perusahaan adalah citra dan brand awareness masyarakat terhadap perusahaan. Public relations memiliki peran yang sangat besar dalam hal tersebut, dan sistem state of being dengan keberadaan posisi public relations dalam struktural perusahaan akan jauh lebih mempermudah pembentukan citra perusahaan, hal ini dibuktikan dengan evaluasi sistem methode of communciations yang dianut oleh Radio URBANrkm ternyata cukup menyulitkan pada saat terjadi sebuah krisis dalam perusahaan. Begitupula dengan rangkap jabatan lainnya seperti posisi Music Director dan Marketing Communications, serta IT dan Traffic. Akan lebih baik ketika tim itu kecil guna mengefektifkan kinerja sumber daya manusia namun posisi jabatan tepat pada sasaran.

Ketiga dalam tahap pengarahan, tidak terlalu banyak evaluasi, namun cukup perlu ditingkatkan saja sistem pengarahannya yang satu komando dan efektif. Keempat, dalam tahapan pengawasan yang perlu dievaluasi adalah pimpinan harus lebih mengantisipasi cara pengawasan melalui social media yang sangat membantu dan menguntungkan, namun juga dapat memberikan jarak terhadap hubungan personal antara pimpinan dan bawahan, yang harus diperhatikan adalah komunikasi langsung dapat membuat manusia lebih mengenali karakter dan menumbuhkan sense of belonging terhadap lawan komunikasinya, pendekatan personal dalam ruang lingkup human relations melalui komunikasi langsung sangat dibutuhkan oleh karyawan untuk meningkatkan etos kerja dan motivasi kerjanya.

Beberapa tahapan yang dilakukan oleh Radio URBANrkm maupun Smooth Radio adalah perubahan penyebutan frekuensi, perubahan lagu - lagu, perubahan nama, dan perubahan logo hingga launching celebretions yang sedang dipersiapkan. Rebranding secara definisi berarti perubahan identitas, yang harus dilihat sebagai sebuah keputusan strategis dengan rencaana yang matang.(Daly dan Moloney, 2004) Identitas sebuah radio yang paling menonjol adalah nama, logo dan karakter serta jenis lagu yang diputarkan, maka penulis berpendapat bahwa perubahan identitas yang dilakukan oleh Radio URBANrkm maupun Smooth Radio sudah sangat baik, karena melalui perubahan pada titik - titik identitas tersebut mampu memunculkan brand awereness dan citra serta karakter dari radio tersebut.

Dalam penelitian ini, penulis mengkaji tentang tahapan rebranding serta 
keterkaitannya dengan public relations.Apakah memang rebranding merupakan kajian dari public relations? Apakah public relations memiliki peran didalam rebranding sebuah perusahaan?Bagaimana keterlibatan public relations dalam rebranding tersebut?

Hasil dari penelitian ini menunjukan bahwa, Radio URBANrkm tidak memiliki divisi public relations, dengan kata lain menganut sistem methode of communications begitupun Smooth Radio pada awal terbentuknya perusahaan ini belum memiliki sumber daya manusia yang menempati posisi tersebut, namun akan segera dipersiapkan.

Penulis menyimpulkan bahwa, walaupun sistem yang dianut perusahaan adalah methode of communciations, namun kegiatan public relations tetap ada dan tetap dilaksanakan, terbukti dengan dua point dalam sasaran kegiatan public relations tersebut sesuai dengan kegiatan yang dilaksanakan oleh Radio URBANrkm maupun Smooth Radio. Point pertama adalah membangun identitas dan citra perusahaan, hal ini dibuktikan dengan dilakukannya perubahan- perubahan hingga pengenalan identitas baru dari perusahaan yakni identitas Smooth Radio yang bertujuan untuk membangun citra dari Smooth Radio. Point kedua adalah menghadapi krisis, hal ini dibuktikan dengan penanganan karyawan - karyawan
Radio URBANrkm terhadap respon stakeholder eksternal yakni klient dan pendengar, mereka merespon pertanyaan dan tanggapan dari publik terkait rebranding tersebut baik secara langsung maupun melalui media social.

Sebagai sebuah perusahaan yang baru terbentuk, tujuan yang paling sesuai dari keempat tujuan lainnya di atas adalah menciptakan citra yang baik. Jika dikaitkan dengan kegiatan, tahapan, maupun program yang telah dilakukan oleh Smooth Radio, melalui perubahan identitas nya yang berbeda dengan Radio URBANrkm hingga launching celebrations yang dipersiapkan, semua hal tersebut merupakan kegiatan public relations yang bertujuan untuk membentuk citra perusahaan yang sesuai dengan harapan dari perusahaan. Hasil penelitian membuktikan bahwa, kegiatan public relations yang dilakukan oleh Smooth Radio telah sangat baik, terbukti dengan kesadaran beberapa sample pendengar setia Radio URBANrkm yang menjadi informan pada penelitian ini menyampaikan pendapatnya bahwa mereka sudah mulai menyadari citra dari Smooth Radio berbeda dengan Radio URBANrkm dan seperti apa citra dari Smooth Radio tersebut.

\section{SIMPULAN}

Berdasarkan penelitian yang telah dilakukan oleh penulis di Radio 
URBANrkm hingga menjadi Smooth Radio dengan judul Implementasi Rebranding Radio URBANrkm 99.5 FM Guna Menciptakan Citra Baru Perusahaan. Penulis menyimpulkan sebagai berikut:

a. Radio Smooth FM melakukan implementasi rebranding dengan lima bauran implementasi yakni pengorganisasian, penyusunan, pengarahan, pengawasan dan penilaian, hal tersebut mencakup :

- Pengorganisasian : Smooth Radio merencanakan posisi - posisi yang akan ada di struktural perusahaan dan membuat konsep dari kegiatan kegiatan, tahapan dan program pembentukan citra yang akan dilaksanakan.

- Penyusunan: Smooth Radio mengisi posisi - posisi yang sudah direncanakan dengan sumber daya manusia yang telah dimiliki.

- Pengarahan : Smooth Radio, top management pada khususnya memberikan pengarahan terhadap pihak - pihak yang terlibat dalam implementasi program tersebut mengenai apa saja yang harus mereka lakukan.

- Pengawasan :top managemen Smooth Radio melakukan pemantauan terhadap hal - hal yang dilakukan oleh karyawan dalam tim rebranding tersebut.
- Penilaian : seluruh pihak terlibat memberikan pendapatnya mengenai kesesuaian rencana dengan realisasi dan memberi pendapatnya untuk perbaikan.

b. Selain dari kelima bauran implementasi, Smooth Radio membuat perubahan perubahan identitas yang dimaksudkan untuk menciptakan citra baru perusahaan, perubahan tersebut meliputi perubahan penyebutan frekuensi, perubahan playlist lagu, perubahan nama, dan perubahan logo.

c. Hasil penelitian menunjukan bahwa setiap tahapan demi tahapan dalam implementasi sudah cukup baik namun perlu diperbaiki dari beberapa aspek.Hasil penelitian juga menunjukan bahwa tahapan dan kegiatan yang dilakukan oleh Radio URBANrkm maupun Smooth Radio sudah cukup berhasil dalam menciptakan citra baru perusahaan yakni citra Smooth Radio yang berbeda dari Radio URBANrkm.

\section{DAFTAR PUSTAKA}

Butterick, Keith 2012. Pengantar Public Relations.Jakarta : PT. Rajagrafindo Persada

Daly, Aidan dan Moloney, Deirdre. 2004. Managing Coorporate Rebranding. Irish Marketing Review

Diyanti, Dwitasari. 2012. Strategi Marketing Public Relations Dalam Proses Rebranding. Skripsi 
Hubungan Masyarakat, Departemen Ilmu Komunikasi, Fakultas Ilmu Sosial dan Ilmu Politik, Universitas Indonesia

Effendy, Onong Uchjana. 2006. Hubungan Masyarakat : Suatu Studi Komunikasi. Bandung : Remaja Rosdakarya

Henslowe, Philip. 2000. The Art and Science of Public Relations Vol. 3. New Delhi: Crest Publishing House

Iriantara, Yosal . 2010. Community Relations, Konsep dan Aplikasinya.Bandung : Simbiosa Rekatama Media

Kasali, Rhenald. 2003. Manajemen Public Relations, Konsep dan Aplikasinya di Indonesia. Jakarta : Pustaka Utama Gravity

Kasali, Rhenald. 2003. Modern PR. Jakarta: PustakaUtama Gravity

Mulyana, Deddy. 2010. Ilmu Komunikasi Suatu Pengantar. Bandung :

PT. Remaja Rosdakarya

Muzellec, L. Doogan, M, dan Lambkin, M. 2003. Coorporate Rebranding - An Exploratory Review. Vol.16 No.2 Hal.31

Nova, Firsan. 2009. Crisis Public Relations (Bagaimana PR Menangani Krisis Perusahaan?) .Jakarta : PT. Grasindo
Olii, Helena. 2007. Opini Publik. Jakarta : PT. Indeks

Nurjaman, Kadar dan Khaerul Umam.Komunikasi dan Public Relations.Bandung : Pustaka Setia, 2012

Riswandi.2009. Definisi Komunikasi dan Tingkataan Proses Komunikasi.Yogyakarta : PT.Graha Ilmu

Ruslan, Rosady. 2010. Manajemen Public Relations dan Media Komunikasi. Jakarta : Rajagrafindo Persada

Wiryanto.2006 .Pengantar Ilmu Komunikasi. Jakarta : PT.Grasindo

Yulianita, Neni. 2007. Dasar-dasar Public Relations. Penerbit : LPPM UNISBA, Bandung

Sumber lain:

http://library.binus.ac.id/eColls/eThesisdoc /Bab2/Bab\%202_08-38.pdf

www.urbanrkm.com

(Diakses pada tanggal 26 Februari 2015 Pukul 17:41) 
